\title{
ORAÇÕES ADVERBIAIS INTRODUZIDAS POR SEM (QUE) + VERBO: RELAÇÃO DE REALCE OU DE EXTENSÃO?
}

\author{
Camilo Rosa SILVA ${ }^{1}$ \\ Marta Anaísa Bezerra RAMOS ${ }^{2}$
}

Resumo: Neste artigo, analisamos um tipo de oração adverbial que apresenta duas características peculiares: é uma oração fixa, para a qual não há uma estrutura correspondente sob a forma desenvolvida; e expressa sentido de adição, típico de orações coordenadas. Trata-se de um uso próprio da combinação sem falar.../sem apontar.../sem contar... Embora a função de juntor seja atribuída à conjunção, já partimos, aqui, do princípio de que a preposição, diante de forma verbal não-finita, recategorizou-se como conector, apesar de as gramáticas só reconhecerem essa função juntiva da preposição quando esta integra uma locução conjuntiva, no caso em foco, a locução sem que. Assim, neste estudo, além de evidenciarmos a recategorização da preposição sem como conector, defendemos, a partir de uma pequena amostra de trechos de artigos de opinião, bem como de entrevistas, que esse conector se reveste de sentidos diversos, não rotulados pela tradição, dentre os quais destacamos o de adição. Ressaltamos, também, a interveniência de fatores discursivos atuantes na gramática, provocando uma reflexão sobre a abordagem dos mecanismos de articulação oracional. Para atingirmos os propósitos referidos, expomos concepções de gramáticos e linguistas como Bechara (2003) e Azeredo (2000, 2014), Longhin-Thomazi (2004), Castilho (2010), Ilari (2008), Decat (2001, 2011), Oliveira (2000).

Palavras-chave: Hipotaxe. Transpositor sem. Recategorização.

\footnotetext{
${ }^{1}$ UFPB - Universidade Federal da Paraíba - Programa de Pós-graduação em Linguística. João Pessoa Paraíba - Brasil. 58038-521 - camilorosa@gmail.com

${ }^{2}$ UEPB - Universidade Estadual da Paraíba - Departamento de Letras. Campina Grande - Paraíba - Brasil. 58400-520-martaanaisa@gmail.com
}

http://dx.doi.org/10.21165/gel.v14i2.1811 


\section{Introdução}

$\mathrm{Na}$ perspectiva dominante entre os gramáticos considerados tradicionais, os elementos linguísticos são abrigados em diferentes classes, considerando-se as semelhanças entre conjuntos de traços morfossintáticos e semânticos. Entretanto, conforme já explicitado em Ramos e Silva (2016, p. 274), na dinâmica da língua em uso, ocorrem deslizamentos de itens que funcionam nas fronteiras interclasses, o que coloca em xeque "a visão de que as categorias são discretas". Já é sabido, também, que "esses desvios não ocorrem de forma abrupta, nem implicam, necessariamente, casos de mudança categorial, sendo explicados pela teoria da gramaticalização como extensão de função".

Na visão corrente entre as gramáticas normativas, a preposição é tratada como uma classe gramatical cuja função consiste em ligar dois termos, estabelecendo uma relação de dependência entre os denominados "termo regente" e "termo regido". Geralmente, as referências apontam para a concepção de um termo dependente, sem qualquer autonomia, que se adjunge a substantivos, adjetivos, verbos e advérbios, em torno dos quais são ativadas relações gramaticais, seja em sintagmas nominais ou até mesmo em orações (BECHARA, 2003).

Uma busca, em gramáticas diversas, sobre os sentidos expressos pela preposição sem, pela locução conjuntiva sem que e os tipos de relações sintático-semânticas expressos por orações introduzidas por esses transpositores nos conduziu à seguinte constatação:

i) no caso da preposição, alguns autores, a exemplo de Barros (1985), Bechara (2003) e Vilela e Koch (2001), não tratam desse aspecto; já Neves (2000), Cunha e Cintra (2001) e Lima (2002) citam as noções de subtração, ausência, privação;

ii) em se tratando da locução conjuntiva, enquanto Barros (1985) menciona os valores de condição, concessão e consequência, aos quais Bechara (2003) acrescenta negação de consequência, negação de causa e ainda modo, Vilela e Koch (2001) se referem apenas ao valor de concessão, Cunha e Cintra (2001) e Lima (2002) citam apenas condição; e Neves (2000), condição e modo. 
iii) sobre as relações estabelecidas entre as orações, tem-se a relação de adjunção, daí a classificação de adverbiais; às noções já indicadas para esses conectores, Barros (1985) acrescenta o matiz de tempo; Bechara (2003), os de causa e modo; Neves (2000), condição e modo; Lima (2002) acrescenta concessão e consequência; Vilela e Koch (2001) citam apenas modo; e Cunha e Cintra (2001) não abordam esse ponto.

À primeira vista, depreendemos que é bastante heterogêneo o tratamento destinado a essas formas gramaticais ${ }^{3}$. Cabe destacar que, em se tratando dos sentidos expressos pela locução conjuntiva, predominam os valores de condição e concessão.

Por outro lado, em meio às orações encabeçadas pelos transpositores em foco, um modelo estrutural se destaca, por apresentar propriedades sintáticas e semânticodiscursivas bem peculiares: sob o primeiro aspecto, trata-se de uma estrutura fixa, para a qual não há uma estrutura de correspondência sob a forma desenvolvida, como normalmente ocorre com as orações adverbiais. Além disso, ela se apresenta na segunda posição, após uma vírgula ou, mais frequentemente, como unidade de informação independente, após ponto ou travessão. Sob o aspecto semântico, é uma estrutura que sempre acrescenta uma informação que serve como argumento mais forte numa escala de argumentatividade. O excerto abaixo, que faz parte de uma amostra constituída de 12 , de um total de 21 ocorrências ${ }^{4}$, extraídas de artigos de opinião ou entrevistas (apenas três separadas por vírgula), ilustra esse tipo de uso:

(1) “Época - O governo brasileiro diz que a vacinação atingiu 70\% do público-alvo: 73 milhões de pessoas, $37 \%$ dos brasileiros.

\footnotetext{
${ }^{3}$ É importante esclarecer que, embora as gramáticas destinem uma seção à listagem dos valores das preposições, no caso específico do sem, normalmente, se fazem observações sob a indicação de "particularidades", fato também observado em relação à locução sem que. Na gramática organizada por Mira Mateus et al. (2003), por exemplo, há menção a essa preposição quando do estudo do sintagma preposicional, na parte referente às categorias sintáticas; mas ela não está entre as preposições cujos valores são discutidos e exemplificados.

${ }^{4}$ A amostra usada nesta análise faz parte de um corpus mais amplo, constituído por textos de natureza argumentativa, extraídos de três revistas semanais: Época (EP), IstoÉ (IÉ) e Veja (VJ). Nele, constatamos 295 ocorrências da estrutura sem + [SN/SAdv.] + infinitivo, distribuídas entre funções, como: concessão (108), condição (27), (negação de) consequência (66), modo (66), adição (21), tempo (1), causa (3) e modalização (3).
} 
Oxford - Vacinar 70\% do público-alvo num país enorme como o Brasil é um porcentual altíssimo. Vocês estão melhor que muitos países da Europa e os Estados Unidos, onde, em média, só metade do público aderiu à campanha. Sem falar em dezenas de países da África, Ásia e América Latina onde quase ninguém foi imunizado”. (EP, Ent., 14/06/2010)

Nesse excerto, a menção aos países nos quais "quase ninguém foi imunizado" constitui uma ressalva, vindo a fortalecer a tese enunciada - o altíssimo grau de adesão à campanha de vacinação - pois se o Brasil está em vantagem em relação a países da Europa e Estados Unidos, a vantagem aumenta na comparação com países da África, Ásia e América Latina.

Dentre as gramáticas referidas, apenas uma delas, a de Bechara (2003, p. 506), expõe um exemplo dessa natureza, qual seja: "Estes foram os melhores teatrólogos, sem falar em Machado de Assis e Franklin Távora, mais ilustres no romance e no conto". Mas, cumpre esclarecer que o autor considera, nesse caso, a expressão de um sentido de modo. Ora, a afirmação feita no período é de que, além dos teatrólogos citados, integram o grupo dos melhores dois outros expoentes, estes no campo do romance e do conto. Logo, há uma relação de inclusão, de forma que a interpretação de acréscimo seria mais apropriada que a de modo, sugerida pelo autor.

Essa estrutura linguística chama-nos a atenção porque, ao mesmo tempo em que a segunda oração mantém uma relação de dependência com a oração matriz, aspecto reforçado, em alguns casos, pelo uso do demonstrativo neutro (isso sem falar), o que caracteriza a hipotaxe adverbial, essa unidade informacional pode se constituir como um ato de fala de comentário do autor. Nesse sentido, traduziria ressalva, esclarecimento, ironia, ênfase, entre outras funções discursivas, o que a aproximaria das estruturas coordenadas; nesse caso específico, das aditivas - esse matiz semântico, porém, não consta no rol das relações adverbiais. Vejamos as estruturas coordenadas no excerto a seguir:

(2) Motivo de grande alvoroço nas redes foram as dúvidas em relação ao que sairá do currículo obrigatório, que atualmente contém treze disciplinas. Especulou-se de tudo, $\boldsymbol{e}$ se trata de mera especulação mesmo. (VJ, Report. 28/09/16) 
Face ao exposto, este artigo segue na direção de tentar mostrar que o padrão estrutural em análise mantém uma relação de dependência com a oração matriz, o que caracteriza a hipotaxe adverbial, mas também se identifica com as estruturas classificadas por Halliday (1985) como de expansão no plano lógico-semântico, o que contraria a ideia de que orações adverbiais são estruturas de realce, ou seja, satélites. Ademais, a função discursiva desse tipo de oração se sobrepõe à função semântica, como reforçam as inserções (ou orações parentéticas), razão de Decat (2001, p. 106) afirmar que, apesar de as orações adverbiais aparentarem ser encaixadas, tendo em vista funcionarem como parte de outra oração, têm "mais que uma função gramatical, uma função discursiva, no sentido de orientar o ouvinte para a mensagem que se quer transmitir, organizando, assim, a forma do discurso". Comparem-se os exemplos a seguir relacionados:

(3) O esforço financeiro para sacudir a grade privada sinaliza o que as públicas terão pela frente. [...] $\boldsymbol{E}$ ainda falta falar de Enem, tema que, sim, já está deixando as escolas particulares de cabelo em pé. (VJ, Report. 28/09/16)

(4) $[\ldots]$ O pesquisador no Brasil faz malabarismo com sua escassa verba - para poder adquirir, por exemplo, reagentes químicos básicos à sua pesquisa. Isso para não falar da precária infraestrutura dos prédios. (VJ, Art., 27/07/16)

(5) [...] Dificilmente o Brasil daria o salto educacional de que precisa apenas com a privatização das escolas: haveria grande concorrência pelos melhores alunos, mas isso não necessariamente melhoraria o nível do ensino como um todo. Sem falar no papel da escola como ambiente socializador e desenvolvedor de uma identidade nacional. [...] (VJ, Art., 14/09/11)

Assim como em (3), a oração introduzida pelo conector $e$ acrescenta uma informação relativa ao Enem, que, discursivamente, reforça a argumentação de que há muitos aspectos preocupantes dentre as reformulações do ensino médio, e, em (4), a preposição para junto ao não assume a mesma função de sem falar, incluindo na discussão outro problema que afeta a comunidade acadêmica, a última informação, em 
(5), relativa à função de socialização da escola, consiste em um adendo, apontando mais um requisito importante para que o Brasil, de fato, dê o necessário salto educacional.

Logo, objetivamos destacar a assimilação do valor aditivo pelo transpositor sem, rótulo não apontado pela tradição na listagem de sentidos expressos pelas orações adverbiais; e refletir sobre as abordagens dos mecanismos de articulação oracional, destacando a interveniência de fatores discursivos na gramática. Tomamos, para análise, uma pequena amostra de trechos de artigos de opinião, bem como de entrevistas, extraídos dos periódicos Veja e Época. Na exposição, reportamo-nos às concepções de gramáticos como Bechara (2003), Azeredo (2000, 2014), Mira Mateus (1989), entre outros, além de linguistas vinculados ao funcionalismo, dentre os quais, Neves (2000), Longhin-Thomazi (2004), Ilari (2008) e Castilho (2010).

Além dessas considerações iniciais, discutimos, nas seções (2) e (3), respectivamente, sobre o caráter adverbial e a classificação semântica das orações em estudo; em (4), passamos à análise dos dados, pondo em evidência o papel argumentativo dessas orações; e, em seguida, tecemos as considerações finais.

\section{O caráter adverbial das orações introduzidas por sem falar...}

Nesta seção, fazemos um esboço de parâmetros considerados por alguns funcionalistas como Halliday (1985), Haiman e Thompson (1984), Lehmann (1988), Hopper e Traugott (1993), entre outros, para a análise de orações complexas. Não obstante algumas divergências nas propostas, dois pontos são convergentes:

i) o de que os rótulos coordenação e subordinação não abrigam os diferentes modelos oracionais existentes, de modo que não se pode fazer a correspondência entre parataxe/coordenação, de um lado, e hipotaxe/subordinação, de outro;

ii) a adoção da ideia de continuum estrutural, considerando em maior ou menor medida aspectos sintáticos, lógico-semânticos e discursivos. Essa postura é assentada na visão de que, no processo de junção, as orações exibem diferentes graus de vinculação sintática, fato motivado, também, pela proximidade semântica entre os eventos descritos nas duas partes constitutivas da oração complexa. 
Halliday (1985) estabelece dois eixos para a análise das orações complexas - o sistema tático ${ }^{5}$ e o sistema lógico-semântico. Neste segundo eixo, podem-se distinguir dois tipos de relação: de expansão e de projeção. A primeira delas, a expansão, contempla as relações lógico-semânticas como: elaboração, extensão e realce. Nesse último grupo, situam-se os casos em que uma oração qualifica a outra quanto a tempo, lugar, modo, causa ou condição. Trata-se das orações adverbiais.

Haiman e Thompson (1984) consideram a combinação que se estabelece entre orações adverbiais e as outras orações, subclassificando-as em dois tipos, a saber: a) relação núcleo/satélite e b) relação de listagem. A diferença entre esses dois grupos está relacionada à quantidade de texto com que a oração adverbial se articula. Assim, no primeiro caso, a articulação se dá entre duas sentenças - a matriz (núcleo) e a adverbial (satélite); no segundo, mais de uma oração adverbial; logo, vários satélites, vinculados numa relação paradigmática (listagem), mantêm uma relação hipotática com a matriz.

Lehmann (1988) e Hopper e Traugott (1993) compartilham da ideia de que as cláusulas que formam a oração complexa refletem diferentes graus de integração. Nessa perspectiva, Lehmann (1988, p. 217) analisa as orações a partir de três critérios gerais: i) autonomia ou integração de cláusulas subordinadas; ii) expansão ou redução da cláusula subordinada ou principal; e iii) isolamento ou articulação de cláusulas, correlacionados com os parâmetros de avaliação abaixo listados, em pares, respectivamente, a saber:

i) 1. rebaixamento hierárquico da cláusula subordinada; 2. nível sintático do constituinte ao qual a oração subordinada se vincula;

ii) 3. dessentencialização da subordinada; 4. gramaticalização do verbo principal;

iii) 5. entrelaçamento das duas orações; 6. explicitude da articulação.

De acordo com o autor, as tipologias oracionais atendem a um continuum de organização, obedecendo a um trajeto conforme o qual, no polo à esquerda, situam-se as orações cujo vínculo é mais fraco, a exemplo das sentenças de igual estatuto sintático (paratáticas); no polo à direita, ficam as orações cujo vínculo é mais forte, ou seja, as

\footnotetext{
${ }^{5}$ Este eixo, segundo Halliday (1985), leva em conta a correlação entre elementos, podendo-se distinguir entre relações paratáticas, hipotáticas e de encaixamento.
} 
sentenças que se integram a outro constituinte da oração principal (é o caso das sentenças encaixadas ou subordinadas) e, no polo intermediário, estão cláusulas adverbiais, cláusulas nominais dessentencializadas, cláusulas correlatas, etc. Os critérios indicados por Lehmann (1988) são resgatados, sobretudo, em estudos que tratam da gramaticalização de orações ${ }^{6}$ que representam atitudes dos falantes, as chamadas orações modalizadoras, advindas de orações complexas formadas com orações completivas. Mas também se aplicam a orações adverbiais que tendem à nominalização.

Hopper e Traugott (1993), considerando parâmetros sintáticos e semânticodiscursivos e adotando a ideia de continuum, também sugerem que o processo de junção das orações segue a direção de menor para maior integração de cláusulas e, em decorrência desse fator, o elo oracional é mínima ou maximamente explicitado, como revela o esquema proposto pelos autores:

Quadro 1: Continuum de (in)dependência e encaixamento

\begin{tabular}{|c|c|c|c|}
\hline $\begin{array}{l}\text { PARATAXE } \\
\text { (independência) } \\
\text { núcleo } \\
\text { integração mínima } \\
\text { ligação explícita máxima }\end{array}$ & $\begin{array}{l}\text { HIPOTAXE } \\
\text { (interdependência) }\end{array}$ & $>$ & $\begin{array}{r}\text { SUBORDINAÇÃO } \\
\text { (dependência) } \\
\text { margem } \\
\text { integração máxima } \\
\text { ligação explícita mínima }\end{array}$ \\
\hline
\end{tabular}

Fonte: Hopper e Traugott (1993)

A contribuição dessas últimas abordagens consiste em permitir que se reconheçam com mais segurança as propriedades das diversas tipologias oracionais, por conciliar os critérios dependência e encaixamento. Além disso, a consideração do eixo lógicosemântico sinalizado por Halliday (1985), conforme argumenta Braga (2001, p. 25), "fornece respaldo à intuição de que uma mesma relação semântica pode ser codificada por diferentes estratégias sintáticas". Com isso, evita-se que o estudo dos processos de combinação oracional se restrinja à mera associação entre tipologia de oração e/ou

\footnotetext{
${ }^{6}$ Ilustram casos de modalização de estruturas, a exemplo de "acho" e "parece", em que ocorre redução ou dessentencialização de orações; e estruturas cristalizadas como "vai ver que", que revela o uso gramaticalizado do verbo da oração principal, correspondendo ao advérbio provavelmente. Quanto às adverbiais, servem de ilustração as orações finais. Azevedo (2000) apresenta, em sua tese, uma tipologia de estruturas que expressa finalidade, contemplando orações desenvolvidas e reduzidas, além de estruturas fortemente nominalizadas, como "Os países que, historicamente, mais contribuíram para a contaminação ambiental têm uma responsabilidade maior a respeito.".
} 
tipologia de relação semântica, em conformidade com o conector que realiza o elo oracional.

Em relação às estruturas oracionais de que o transpositor $\operatorname{sem}^{7}$ faz parte, Neves (2000), tratando do mecanismo da "junção", mais especificamente das preposições não introdutoras de argumento, comenta que "a preposição SEM estabelece relações semânticas no sintagma verbal (adjunto adverbial)" "(NEVES, 2000, p. 729). Dentre os contextos estruturais elencados pela autora, interessa-nos, aqui, aquele no qual a preposição habilita uma unidade linguística (oração) a assumir uma nova função - de adjunto adverbial ou predicativo; especialmente a primeira, a saber: Verbo + SEM + sintagma nominal ou oração (não-argumental).

Nesse contexto, a autora faz alusão às relações de modo e de condição. Para o primeiro caso, cita dois exemplos, um sob a forma reduzida: "Sem olhar para o cliente, contava o dinheiro na gaveta." (CE) e outro sob a forma desenvolvida, em que aparece a locução conjuntiva: "Empurrava a cadeira e saía, sem que o patrão corresse atrás; em relação ao segundo sentido, de condição, cita apenas um exemplo com oração desenvolvida: “A democracia não será efetiva sem liberdade de informação e não será exercida sem que esta esteja assegurada a todos os veículos de comunicação social." (AP).

Também na gramática organizada por Mira Mateus (1989), contempla-se o sentido deste item na parte dedicada ao estudo da negação. Conforme assinala Matos (2003, p. 773), a preposição sem integra, juntamente ao não e ao nem, o grupo dos "marcadores de negação". Dentre as funções que esse marcador assume, estão: preposição, complementador negativo e afixo. Enquadram-se na segunda função o uso das orações subordinadas reduzidas de infinitivo, daí a autora ressalvar que, nas frases finitas, esse complementador faz parte da locução sem que.

Até aqui, destacamos a função de adjunção como propriedade que distingue as subordinadas adverbiais das substantivas (ou encaixadas), que são argumentos do verbo. Cabe destacar que Neves (2006, p. 233) esclarece que as informações subsidiárias se anexam "em qualquer das camadas de organização do enunciado: na predicação, na

\footnotetext{
${ }^{7}$ Neves (2000) aborda, ainda, esse item no tópico "modo de expressão da negação", no apêndice relativo ao estudo do advérbio. Segundo a autora, ao lado das partículas não, jamais, nunca e nem, o sem (que) também atua nos sintagmas nominal e adverbial, ou no âmbito da oração.

${ }^{8}$ Grifo da autora.
} 
proposição, no ato de fala". E que, por serem opcionais, essas orações satélites refletem as intenções comunicativas do falante "na sua busca natural do melhor cumprimento de funções do seu enunciado". 9

Por outro lado, não obstante a estrutura em estudo aponte para um elemento subordinativo, dada a presença da preposição, do verbo na forma não finita, além do vínculo com a unidade precedente, marcada pelo uso do anafórico "isso" em várias ocorrências, há um traço típico das adverbiais que não se evidencia nessa estrutura: a reversibilidade. E, na medida em que sua função é expandir a informação precedente, depreende-se um traço em comum com as coordenadas, particularmente com as aditivas assimétricas, as não-reversíveis: a função discursiva ${ }^{10}$ de introduzir comentário do falante.

Para concluir esta seção, reforçamos que, numa perspectiva funcionalista, o estudo das orações adverbiais ultrapassa a identificação, no nível das sentenças, do tipo de informação que é adicionada à oração matriz por meio da associação à tipologia de advérbios. Conforme assinala Decat (2001), além de nem sempre ocorrer tal correspondência, pode também a oração adverbial ter como alvo/escopo um grupo de sentenças. Portanto, está-se no nível textual e não no sentencial. O reconhecimento dessa particularidade das orações adverbiais faz com que funcionalistas como Castilho, entre outros, prefiram descrevê-las como um princípio de organização do discurso, ou "como um caso de "combinação de cláusulas"” (CASTILHO, 2010, p. 371).

\section{Estruturas com (e) (isso) sem falar... e a relação de adição}

Não são raras as críticas à abordagem tradicional das orações adverbiais, devido à vinculação da classificação semântica dessas orações ao valor expresso pelo conector $^{11}$

\footnotetext{
${ }^{9}$ A autora é, nesse tópico, assumidamente influenciada por Dik (1978).

${ }^{10}$ A equivalência estrutural dos membros da coordenação é o que permite a reversibilidade das estruturas, o que caracteriza a adição simétrica; propriedade que não é válida para a adição assimétrica, devendo ficar claro que não são razões sintáticas que determinam a não-reversibilidade, de modo que a inteligibilidade da combinação das orações será garantida desde que o leitor resgate informações prévias - conhecimento de mundo ou conhecimento partilhado no processo enunciativo (PEZATTI; LONGHIN-THOMAZI, 2008, p. 889).

${ }^{11}$ Segundo Decat (2001, p. 123), a possibilidade de um conectivo permitir mais de uma inferência de sentido possivelmente é consequência do "esvaziamento semântico de algumas expressões conjuntivas [...]". Sendo assim, "a decisão sobre qual das duas inferências é a predominante só será possível no nível do discurso.".
} 
que as encabeça. Halliday (1985), como já afirmado, defende que a articulação entre uma oração matriz e uma adverbial, também denominada de cláusula de realce, resulta de escolhas discursivas. Sendo assim, informações implícitas podem emergir da combinação entre cláusulas, de modo que a classificação das orações adverbiais não tem, necessariamente, de obedecer à tipologia das conjunções adverbiais.

Quanto ao tratamento das gramáticas tradicionais à classe das conjunções, sob uma perspectiva semântica ${ }^{12}$, Ilari (2008) o considera restrito, em virtude de o critério de classificação dessas formas gramaticais ter por base a dicotomia coordenação/subordinação. Daí, segundo o autor, "num estudo semântico das conjunções, uma das consequências pode ser a de recusar à oposição coordenativas/subordinativas o lugar privilegiado de que tem desfrutado" (ILARI, 2008, p. 828).

Prova manifesta de quanto os valores semânticos das conjunções se sobrepõem, a ponto de não se poder atribuir uma classificação rígida, é a maneira como Azeredo (2000) e Castilho (2010) agrupam as orações adverbiais, com base nas afinidades de sentido, como explicitado no quadro, a seguir:

Quadro 2: Distribuição das orações adverbiais conforme afinidade de sentido

\begin{tabular}{|c|l|}
\hline A & Causalidade: causais, condicionais, finais e consecutivas \\
Z & \\
E & Situação: temporais, locativas e proporcionais \\
R & \\
E & Comparação: comparativas e conformativas \\
D & \\
O & Contraste: contrastivas e concessivas \\
\hline C & \\
A & Causalidade: causais, condicionais, concessivas, explicativas e conclusivas \\
S & \\
T & Temporalidade: temporais e proporcionais \\
I & \\
L & Finalidade: finais \\
H & \\
O & \\
\hline
\end{tabular}

Fonte: Elaboração própria a partir da classificação dos autores

\footnotetext{
12 Conforme Ilari (2008), a análise das conjunções da língua natural conduz ao estudo da significação em dois planos: um literal, voltado ao registro de aspectos verifuncionais, e outro voltado para a identificação de implícitos, considerando outras determinações semânticas, explicadas normalmente como implicaturas. (ILARI, 2008, p. 838).
} 
Cabe observar que, na Gramática Houaiss da Língua Portuguesa (AZEREDO, 2014, p. 323-336), há algumas alterações: a antes denominada situação é substituída por temporalidade, que já não contempla as orações locativas; a relação de comparação passa a constituir um subtópico da categoria qualificação, quantificação e orações modais; por fim, há a inclusão de duas categorias de sentido, referidas no item "um par à parte" adição e preterição, sendo representadas por estruturas encabeçadas pelas locuções prepositivas além de e em vez de.

A relação aditiva é normalmente vinculada ao processo de coordenação, definido como um mecanismo de encadeamento de orações que tanto pode se realizar pela simples aposição de sintagmas (nominais ou oracionais) como por meio da conjunção "e", cuja função é de entrelaçamento, sem expressar "nenhuma idéia subsidiária" (BECHARA, 2003, p. 477). Essa característica é também mencionada por Dias de Moraes (1987, p. 15, apud CASTILHO, 2010, p. 345), segundo a qual a função desse item é indicar que cada segmento do conjunto é externo ao outro, mantendo-se o segundo segmento "neutro quanto à direção relativa das informações ou argumentos enunciados”.

Oliveira (2012) $)^{13}$ alerta que o rótulo adição identificava, no português, estruturas coordenadas e correlativas, não havendo menção à possibilidade de uma oração aditiva ser codificada morfossintaticamente pela subordinação. No estudo realizado em torno de orações introduzidas pela expressão além de, a autora chegou à conclusão de que esse modelo oracional se afasta das estruturas adverbiais ou "de realce", por não modificar a oração precedente, aproximando-se, pois, das estruturas classificadas por Halliday (1985) como hipotaxe de extensão, um tipo de relação em que uma oração amplia o significado da outra, ou seja, acrescenta algo novo à oração precedente.

Logo, a proposta de Azeredo (2014) constitui um avanço na abordagem semântica das orações adverbiais, autorizando a visão aqui defendida de que orações introduzidas pela expressão sem falar também expressam adição, inclusive porque esse padrão oracional admite a paráfrase com o conector além de.

\footnotetext{
13 Oliveira (2012) realiza um estudo sobre as orações introduzidas pela expressão além de e esclarece inicialmente que, embora, de modo geral, não haja o reconhecimento de orações subordinadas aditivas, em estudos sobre subordinação em inglês, estruturas formadas com "além de" são incluídas nesse grupo, sendo a presença do verbo na forma não-finita um indício de subordinação. Mas, para ela, esse modelo de oração não modifica a precedente, afastando-se dos critérios que a definiriam como adverbial.
} 


\section{A relação de adição evidenciada nos dados}

A remissão aos conectores $e$ e além de neste estudo se justifica por entendermos que o emprego das orações encabeçadas pela unidade sem falar pode ter a mesma motivação que o de usos evidenciados pelos elementos citados.

No caso específico do $e$, o fato de esse conector se revestir de matizes semânticos como os de adversidade, consequência, condição, etc. afasta a função de estritamente aditivo, o que conduz à distinção entre adição pura e impura (LENKER, 2010), o primeiro caso correspondendo ao sentido prototípico, de soma, e o segundo, às noções secundárias. Oliveira (2012), reportando-se a Geis e Zwicky (1971), destaca que este segundo tipo pode implicar a noção de ênfase argumentativa, caso em que não expressa valores relacionados às noções de temporalidade, tal como se dá com a adição pura, mas que, diferentemente desta, "implica numa relação de assimetria, em que uma proposição ganha maior relevo argumentativo" (OLIVEIRA, 2012, p. 30). Do mesmo modo, do ponto de vista da função comunicativa, a informação adicionada na estrutura iniciada pela unidade sem falar atende não a uma necessidade estrutural, mas textual-discursiva, função também assumida pelo " $\mathrm{e}$ ".

Para comprovar a proximidade dessas estruturas, considerem-se as duas ocorrências abaixo relacionadas, em que a unidade sem falar vem precedida da conjunção aditiva:

(6) “[...] Ainda assim, continuará existindo uma agenda moderna de direitos humanos no Brasil. Quem são as vítimas? Aqueles a quem o Estado nega educação, saúde e segurança, por exemplo. Ou aqueles que morrem nas estradas esburacadas e nas filas dos hospitais. E isso sem falar nos que ainda são torturados nas delegacias ou amontoados nos presídios federais como lixo humano. [...] Esses, que também têm seus direitos suprimidos, não fazem parte da agenda oficial" (IÉ, A, 20/01/2010);

(7) “A algumas quadras do Coliseu, na Via Petroselli, em Roma, há um pequeno monumento à corrupção brasileira. Chama-se FortySeven. Sim, este é o nome de um hotel em Roma, que pertence a ninguém menos que Salvatore Cacciola. [...] 
Mas, no fim, para ele, o crime talvez tenha compensado. Aos 67 anos, Cacciola tem saúde, uma vida de cinema e parte do patrimônio que lhe foi dado pelo BC e sem falar, é claro, nos 47 quartos do FortySeven". (IÉ, A, 31/08/2011)

É pertinente afirmar que, em cada um desses fragmentos, o último período corresponde a um adendo, com informação adicional relativa ao tema em foco: em (6), o escritor inclui no grupo das possíveis vítimas - uma terceira categoria de indivíduos que provavelmente não seriam assim considerados - a dos presidiários que sofrem tortura nos presídios, caracterizados como lixo humano. E em (7), para provar que o crime compensa, o escritor apresenta o hotel FortySevem como mais uma fonte de renda de Cacciola. A seguir, apresentamos duas paráfrases para cada situação - uma com e também/ainda, que remete à noção de inclusão, um valor do $e$; e outra com além de:

(6') [...] Ou aqueles que morrem nas estradas esburacadas e nas filas dos hospitais. $E$ também aqueles que ainda são torturados nas delegacias ou amontoados nos presídios federais como lixo humano. [...]

(6") [...] Ou aqueles que morrem nas estradas esburacadas e nas filas dos hospitais. Além daqueles que ainda são torturados nas delegacias ou amontoados nos presídios federais como lixo humano. [...]

(7') [...] Aos 67 anos, Cacciola tem saúde, uma vida de cinema e parte do patrimônio que lhe foi dado pelo $\mathrm{BC}$ - e também, é claro, os 47 quartos do FortySeven.

(7'’) [...] Aos 67 anos, Cacciola tem saúde, uma vida de cinema e parte do patrimônio que lhe foi dado pelo BC - além, é claro, dos 47 quartos do FortySeven.

Nos excertos a seguir, o conector $e$ já não aparece, sendo a função de acréscimo assumida pela unidade sem + infinitivo. O verbo falar é o mais recorrente ((8), (11), (12)), porém outros verbos também podem ocupar essa posição $((9),(10))$ : 
(8) “O governo paga $12,5 \%$ de juros ao ano para financiar sua dívida, mas o BNDES cobra $6 \%$ por seus empréstimos. Isso não é subsídio? Não gosto de usar o termo subsídio. Claro que isso acarreta, sim, um custo para o Tesouro. Mas nossos estudos mostram que o retorno em forma de receitas para as empresas e mais arrecadação de impostos e empregos - sem falar no lucro que o BNDES repassa ao governo - compensam tal custo. Não estamos emprestando dinheiro de graça a ninguém. [...]” (VJ, E, 27/07/11)

(9) “[...] Também diziam que a Varig devia os tubos aos credores, sem apontar que ela também era (e ainda é) credora do governo. E que era oligopolista agindo como se fosse uma estatal. Etc. Etc.” (ÉP, A, 16/08/2010)

(10) "Esses três casos são apenas uma pequena amostra do muito que o Japão já fez pelo Brasil, sem considerar a inestimável contribuição da colônia nipônica nos últimos 100 anos. [...]” (IÉ, A, 23/03/2011)

(11) “[...] Enquanto isso, nossas exportações para a China - o país que mais cresce no mundo e principal importador de nossas matérias-primas - aumentaram 77\% apenas em quantidade desde a crise, sem falar no ganho de preço. [...]" (IÉ, A, $06 / 04 / 2011)$

(12) “[...] Obras essenciais não andam e muitos projetos da Copa ainda parecem ser apenas projetos. Sem falar nos impactos políticos. [...]” (IÉ, A, 28/12/11).

Em (8), a informação de que o BNDES repassa lucros ao governo aparece intercalada, tendo a função de ênfase, com o propósito de ratificar o argumento de que as vantagens citadas - retorno em forma de receitas e arrecadação de impostos -compensam os custos do Tesouro. Essa estratégia argumentativa se repete nos excertos seguintes, ainda que em (9) e (10) sejam utilizados os verbos apontar e considerar, e as orações não estejam separadas por ponto ou travessão, que sinalizariam uma pausa maior. Seguem as paráfrases com a substituição da unidade formada por sem + verbo por outro conector de valor aditivo: 
(8') [...] nossos estudos mostram que o retorno em forma de receitas para as empresas e mais arrecadação de impostos e empregos - além do lucro que o BNDES repassa ao governo - compensam tal custo.

(9') [...] Também diziam que a Varig devia os tubos aos credores, além do que/disso, ela também era (e ainda é) credora do governo. E que era oligopolista agindo como se fosse uma estatal. Etc. Etc.

(10’) Esses três casos são apenas uma pequena amostra do muito que o Japão já fez pelo Brasil, além da inestimável contribuição da colônia nipônica nos últimos 100 anos. $[\ldots]$

(11') [...] Enquanto isso, nossas exportações para a China - o país que mais cresce no mundo e principal importador de nossas matérias-primas - aumentaram 77\% apenas em quantidade desde a crise, além do ganho de preço. [...]

(12') [...] Obras essenciais não andam e muitos projetos da Copa ainda parecem ser apenas projetos. E ainda tem os impactos políticos. [...]

Lembramos que a proximidade apontada em relação ao processo de coordenação reside no fato de a informação introduzida pela unidade sem falar corresponder a uma extensão e não modificação da oração precedente; e ser uma informação requerida da situação comunicativa.

Para fortalecer a proposição de que a preposição sem, diante de forma verbal infinitiva seguida de complemento, gramaticalizou-se como conjunção, recorremos a uma afirmação de Ilari et al. (2008, p. 768), para quem "o sem pode desempenhar o papel de uma conjunção, intermediando entre sentenças.".

Quanto ao valor aditivo expresso nas estruturas formadas com a expressão sem falar ou outro verbo de valor correspondente, a exemplo da expressão sem apontar/sem contar, demonstramos que esse modelo estrutural pode ser parafraseado por estruturas iniciadas por além de, além do que, e também/ainda, constituindo um uso inovador, na medida em que não modificam uma informação precedente - ao contrário, acrescentam 
uma informação que, numa escala de argumentatividade, consiste em um argumento decisivo em defesa de um ponto de vista. Essas orações, de natureza parentética - daí também serem rotuladas de "desgarradas" (DECAT, 2011) -, representam um padrão de uso específico da estrutura reduzida.

As extensões de sentido, resultantes de transferências de sentido por contiguidade, têm relação com pressões do contexto discursivo, aspecto enfaticamente registrado, quando da menção aos trabalhos de Decat (2001) e Silva (2005), que ressaltaram os processos inferenciais na identificação das relações oracionais. Isso demonstra que é limitado um estudo das orações adverbiais pautado em uma classificação rígida, determinada, sobretudo, pelo tipo de conjunção, o que culmina na mera rotulação de orações coordenadas ou subordinadas, mas não dá conta das especificidades e das sutilezas de sentido que as intencionalidades ativam. Sem falar na força inovadora do componente pragmático.

\section{Considerações finais}

Nosso olhar fixou, como ponto de partida para a discussão proposta neste artigo, o tratamento que a tradição normativista destina à preposição, especialmente, às formas sem/sem que. Pomos em evidência o fato de, nesses compêndios, essa classe ser tratada como mero ligador de termos, cuja função restringe-se a instituir uma relação de dependência entre regente e regido.

Destarte, nosso esforço foi direcionado à tentativa de evidenciar que o escopo de atuação das formas referidas ultrapassa os limites da ligação entre nomes, adjetivos, verbos e advérbios. Assim, chegamos aos usos nos quais as preposições passam a atuar como conectores oracionais, estabelecendo relação da matriz com a estrutura hipotática. Entretanto, sua atuação não se limita a essa função, posto que ativa processos de expansão, tomando-se como referência o eixo lógico-semântico. Essa percepção nos leva a concluir que orações adverbiais não são meras estruturas de realce, os chamados satélites.

A partir daí, defendemos que uma análise do processo de articulação de orações requer a consideração dos componentes sintático, semântico e pragmático, em virtude de 
a atividade linguística refletir as intenções dos falantes, evidenciando a integração das funções ideacional, textual e interacional da linguagem (HALLIDAY, 1985).

Foi assim que destacamos o valor aditivo assumido pelo item sem, ao mesmo tempo em que ressaltamos a interferência relevante que os fatores discursivos exercem na gramática. No caso do sem/sem que, seu papel argumentativo merece ser salientado. Com efeito, a perspectiva funcionalista de lidar com a descrição linguística nos impõe a necessidade de considerar, na análise, além dos dados, os contextos de uso. E, assim, ratificar a inconsistência de análises que rotulem as orações baseadas apenas na classificação cristalizada que os conectores, aprioristicamente, detenham.

SILVA, Camilo Rosa; RAMOS, Marta Anaísa Bezerra. Adverbial clauses introduced by sem (que) + verb: relationship of enhancement or extension? Revista do Gel, v. 14, n. 2, p. 105-124, 2017.

Abstract: In this article, we analyze a type of adverbial clause that presents two very peculiar characteristics: $i)$ it is a fixed clause, for which there is no corresponding structure in the developed form; And ii) expresses sense of addition, typical of coordinated sentences. It is a proper use of the combination sem falar... / sem apontar... I sem contar ... Although the function of juntor is attributed to the conjunction, we already start, here, from the principle that the preposition, before non-finite verbal form, was recategorized as a conjunction, although the grammarians only recognize this junction of the preposition when it integrates a conjunctive locution, to this case in focus, the locution sem que. Thus, in this study, in addition to highlighting the recategorization of the preposition sem as a conjunction, we demonstrate, from a small sample of excerpts from opinion articles, as well as from interviews, that this connector has different meanings, not labeled by tradition, among which we emphasize the one of addition. We also show the intervention of discursive factors in the grammar, provoking a reflection on the mechanisms of sentence articulation. In order to achieve the mentioned purposes, we expose conceptions of grammarians such as Bechara (2003) and Azeredo (2000, 2014), as well as linguists influenced by functionalism, such as Longhin-Thomazi (2004), Ilari (2008), Castilho (2010), Decat (2001, 2011), Oliveira (2000), among others.

Keywords: Adverbial hypotaxis. Transpositor sem. Recategorization.

Submetido em: 21/03/2017.

Aceito em: 07/05/2017. 


\section{Referências}

AZEREDO, J. C. de. Fundamentos de gramática do português. Rio de Janeiro: Jorge Zahar, 2000.

Gramática Houaiss da língua português. São Paulo: Publifolha Zahar, 2014.

AZEVEDO, J. L. F. de. Consequências discursivas e semânticas da mobilidade das orações finais no português escrito. Revista Univ. Rural, Sér. Ciências Humanas, v. 24 (1-2), p. 11-34, jan./jun., 2002.

BARROS, E. M. de. Nova Gramática da língua portuguesa. São Paulo: Atlas, 1985.

BECHARA, E. Moderna gramática portuguesa. 38. ed. Rio de Janeiro: Lucerna, 2003.

BRAGA, M. L. Processos de combinação de orações: enfoques funcionalistas e gramaticalização. SCRIPTA, Belo Horizonte, v. 5, n. 9, p. 23-34, 2. sem., 2001.

CASTILHO, A. T. de. Para uma análise multissistêmica das preposições. In:

CASTILHO, A. T. de. História do português paulista. Campinas:

UNICAMP/Publicações IEL, 2009.

Nova gramática do português brasileiro. São Paulo: Contexto, 2010.

CUNHA, C.; CINTRA, L. F. L. Nova gramática do português contemporâneo. Rio de Janeiro: Nova Fronteira, 2001.

DECAT, M. B. N. A articulação hipotática adverbial no português em uso. In: DECAT, M. B. N. et al. Aspectos da gramática do português. Campinas: Mercado de Letras, 2001 (Coleção Ideias sobre Linguagem).

Estruturas desgarradas em língua portuguesa. Campinas: Pontes, 2011.

DIK, S. Functional grammar. Dordrecht-Holland/Cinnaminson: Foris Publications, 1978.

HAIMAN, J.; THOMPSON, S. Subordination in universal grammar. Proceedings of the tenth meeting of the Berkeley Linguistic Society. Berkeley: Berkeley Linguistics Society, 1984.

HALLIDAY, M. A. K. An introduction to functional grammar. 2. ed. London: Edwards Arnold Publishers Ltd., 1985.

HOPPER, P.; TRAUGOTT, E. Grammaticalization. Cambridge: Cambridge University Press, 1993. 
ILARI, R. As conjunções. In: ILARI, R.; NEVES, M. H. de M. (Org.). Gramática do português culto falado no Brasil. v. 2. Campinas: Editora da UNICAMP, 2008. p. 809-860.

ILARI, R.; CASTILHO, A. T. de; ALMEIDA, M. L. L. de; LEHMANN, C. Towards a typology of clause linkage. In: HAIMAN, J.; THOMPSON, S. A. Clause combining in grammar and discourse. Amsterdam/Philadelphia: John Benjamins Publishing, 1988.

LENKER, U. Argument and rhetoric adverbial connectors in the history of english. Berlin/New York: Walter de Gruyter, 2010.

LIMA, C. H. da R. Gramática normativa da língua portuguesa. Rio de Janeiro: José Olympio, 2002.

LONGHIN-THOMAZI, S. R. Considerações sobre gramaticalização de perífrases conjuncionais de base adverbial. Veredas, Juiz de Fora: UFJF, v. 8, p. 215-232, 2004.

MATOS, G. Estruturas de coordenação. In: MIRA MATEUS, M. H. et alii. Gramática da língua portuguesa. 5. ed. revista e aumentada. Lisboa: Caminho, 2003.

MIRA MATEUS, M. H. et alii. Gramática da língua portuguesa. Lisboa: Caminho, 1989.

Caminho, 2003.

Gramática da língua portuguesa. 5. ed. revista e aumentada. Lisboa:

NEVES, M. H. de M. Gramática de usos do português. São Paulo: Editora da UNESP, 2000.

Texto e gramática. São Paulo: Contexto, 2006.

OLIVEIRA, T. P. de. A hipotaxe de adição. Revista do Gel, São Paulo, v. 9, n. 2, p. $25-$ 45, 2012.

PEZATTI, E. G.; LONGHIN-THOMAZI, S. R. As construções coordenadas. In: ILARI, R.; NEVES, M. H. de M. (Org.). Gramática do português culto falado no Brasil. v. 2. Campinas: Editora da UNICAMP, 2008. p. 865-932.

RAMOS, M. A. B.; SILVA, C. R. A função juntiva da preposição sem: especialização de uso em orações adverbiais reduzidas de infinitivo. Revista Gragoatá, Niterói: UFF, v. 21, n. 40, p. 273-294, 2016.

SILVA, C. R. Mas tem um porém...: mapeamento funcionalista da oposição e seus conectores em editoriais jornalísticos. 2005. 272 f. Tese (Doutorado em Letras) Programa de Pós-graduação em Letras, Universidade Federal da Paraíba, João Pessoa, 2005.

VILELA, M.; KOCH, I. V. Gramática da língua portuguesa. Coimbra: Almedina, 2001. 